\title{
RANCANG BANGUN SISTEM INFORMASI PENGADUAN LAYANAN SARPRAS DI UNIVERSITAS TEKNOLOGI SUMBAWA BERBASIS WEB
}

\author{
Herfandi $^{1^{*}, \text { Yuliadi }^{2}, \text { Sultan Naufal Abdillah }}{ }^{3}$, Eri Sasmita Susanto \\ 1), 2), 3) Teknik Informatika, Universitas Teknologi Sumbawa \\ email:herfandi@uts.ac.id*
}

\begin{abstract}
Abstrak: Penelitian ini bertujuan untuk membangun sistem informasi pengaduan layanan yang ditujukan kepada bidang sarana dan prasarana di Universitas Teknologi Sumbawa (UTS) yang dapat menampung keluhan civitas akademika terkait kondisi sarana dan prasarana di UTS sehingga direktorat sarana dan prasarana dapat melakukan kontrol terhadap pelayanan yang diberikan, dan dapat dicapai kenyamanan dan kepuasan civitas akademika terhadap fasilitas sarana dan prasarana di UTS. Sistem informasi ini dibangun menggunakan framework Laravel dengan menerapkan responsive web design (RWD) dan single page application (SPA) sehingga memberikan akses pada perangkat komputer atau smartphone dengan tampilan rapih dan waktu memuat aplikasi yang cepat.
\end{abstract}

Kata Kunci : Sistem Informasi, Pengaduan, Universitas, Sarpras, Web

Abstract: This study aims to build a service complaint information system addressed to the facilities and infrastructure sector at the University of Technology of Sumbawa (UTS) which can accommodate complaints from the academic community regarding the conditions of facilities and infrastructure at UTS for the directorate of facilities and infrastructure to control the services provided, so that can achieve the comfort and satisfaction of the academic community with the facilities and infrastructure at UTS. This information system was built using the Laravel framework by implementing responsive web design $(R W D)$ and single page application (SPA) so as to provide access to a computer or smartphone device with a neat appearance and fast application loading times.

Keywords : Sistem Informasi, Pengaduan, Universitas, Sarpras, Web

\section{PENDAHULUAN}

Perkembangan teknologi informasi dan komunikasi (TIK) berkembang sangat pesat di berbagai bidang kehidupan sehari-hari manusia. Pesatnya perkembangan TIK telah banyak membantu pekerjaan manusia dari yang awalnya mengandalkan banyak tenaga dan sumber daya, telah berubah menjadi lebih efisien dari segi tenaga dan sumber daya bahkan waktu. Salah satu yang dapat termasuk dari penerapan TIK adalah pengaduan layanan sarana dan prasarana (sarpras) universitas. Pengaduan layanan sarpras universitas merupakan suatu bentuk partisipasi civitas akademika universitas agar penyedia sarpras universitas yang dapat menampung keluhan dari pengadu.

Menurut Naomi (2019:151), pengaduan layanan pada universitas merupakan hal penting karena dengan adanya pengaduan layanan, uinversitas dapat memperbaiki dan meningkatkan kualitas dari pelayanannya [1].

Namun selama ini dirasakan bahwa mekanisme pengaduan di Universitas Teknologi Sumbawa (UTS) belum jelas prosedurnya. Tidak ada tuntunan cara melaporkan kerusakan sarana dan prasarana ataupun wadah untuk menyampaikan masukan dan saran untuk pengadaan fasilitas bagi civitas akademika UTS. Adapun saat ini hanya pihak pengelola sarana dan prasarana yang melakukan pelaporan kerusakan. Padahal seharusnya seluruh civitas akademika UTS dapat terlibat dalam melaporkan kerusakan dan memberikan saran serta masukan demi mencapai kepuasan terhadap fasilitas sarana dan prasarana UTS.

Berdasarkan permasalah yang telah diuraikan di atas maka dalam penelitian ini akan dibangun sistem informasi yang akan memiliki kemampuan menampung pengaduan civitas akademika Universitas Teknologi Sumbawa terhadap kendala fasilitas secara online dengan $R W D$ (responsive web design) dan menerapkan teknologi menyerupai $S P A$ (Single Page Application) serta menerapkan notifikasi email sehingga menciptakan sistem informasi yang dapat dijangkau oleh banyak perangkat dengan performa lebih cepat dari aplikasi non-SPA dan notifikasi email dengan harapan agar sistem informasi ini dapat digunakan untuk pengelolaan pengaduan pada pihak sarpras UTS.

Dengan dibangunnya sistem informasi ini diharapkan dapat membantu pihak layanan universitas dalam memperbaiki fasilitas dan pelayanan sehingga dapat memberikan pelayanan terbaik untuk pengguna fasilitas dan layanan di Universitas Teknologi Sumbawa.

\section{TINJAUAN PUSTAKA}

\section{Landasan Teori}

Jurnal Yayuk Ike Melani (2019) yang berjudul

"Sistem Pengaduan Layanan Akademik Menggunakan Responsive Web Design". Dalam jurnal tersebut dibangun sistem pengaduan layanan akademik untuk STMIK PalComTech. Sistem ini 
dibangun menggunakan web responsive sehingga pengguna dapat mengaksesnya melalui perangkat $P C$ dan Mobile dengan tampilan yang menarik. Penelitian ini menggunakan metode waterfall [2].

Jurnal Suryawan dan Handika (2018) berjudul

"Rancang Bangun Sistem Pengaduan Layanan Akademik STMIK STIKOM Indonesia”. Dalam jurnal tersebut dikembangkan sebuah sistem pengaduan layanan akademik berbasis web yang dapat diakses setiap saat oleh pengguna. Sistem yang dikembangkan ini dapat mengelola data pengguna, membuat aduan, mengenkripsi dan dekripsi data aduan, mengirimkan private key ke email pengguna, serta dapat mengetahui status aduan [3].

Jurnal Anofrizen (2017) dengan judul "Sistem Informasi Pengaduan Masyarakat Program Keluarga Harapan Kota Pekanbaru (Studi Kasus: Dinas Sosial Dan Pemakaman Kota Pekanbaru)". Anofrizen membangun sistem informasi pengaduan masyarakat program keluarga harapan Kota Pekanbaru di Dinas Sosial dan Pemakaman Kota Pekanbaru. Sistem informasi ini menjawab keluhan mengenai sistem informasi yang sudah berjalan seperti kesulitan melakukan pengkategorian dan klasifikasi pengaduan, sering terjadi pencatatan ganda dan ketidaksesuaian pengaduan sehingga proses penanggulangan keluhan sulit dilaksanakan serta banyak kekurangan lainnya [4].

\section{Dasar Teori \\ Rancang Bangun}

Rancang bangun merupakan suatu kegiatan menciptakan sistem dari penerjemahan hasil suatu analisa ke dalam bentuk paket perangkat lunak, baik sistem baru maupun pengembangan dari sistem yang sudah ada [5].

\section{Sistem Informasi}

Sistem adalah suatu jaringan kerja dari prosedur-prosedur yang saling berhubungan, berkumpul bersama-sama untuk melakukan kegiatan atau untuk melakukan sasaran yang tertentu. Sedangkan informasi sendiri adalah data yang diolah menjadi bentuk yang lebih berguna dan lebih berarti bagi penerimanya [6].

Dari definisi-definisi yang dijelaskan di atas, dapat disimpulkan bahwa rancang bangun sistem informasi merupakan suatu kegiatan menciptakan sistem yang terdiri dari prosedur-prosedur yang saling berhubungan untuk mengolah data sehingga dapat berguna bagi penerima atau pengguna.

\section{Pengaduan Layanan}

Pengaduan menurut Peraturan Presiden Republik Indoensia Nomor 76 Tahun 2013 Tentang Pengaduan Pelayanan Publik dalam bab I pasal 1 poin nomor 8, "Pengaduan adalah penyampaian keluhan yang disampaikan pengadu kepada pengelola pengaduan pelayanan publik atas pelayanan pelaksana yang tidak sesuai dengan standar pelayanan, atau pengebaian kewajiban dan/atau pelanggaran larangan oleh peyelenggara" [7].

Menurut Kamus Besar Bahasa Indonesia (KBBI) Layanan adalah perihal atau cara melayani [8].

Sehingga pengaduan layanan merupakan suatu hal yang berkaitan dengan penyampaian keluhan terkait layanan yang tidak sesuai dengan standar pelayanan.

\section{System Development Life Cycle (SDLC)}

System development life cycle atau siklus hidup pengembangan sistem merupakan sebuah proses pembuatan dan pengubahan sistem serta model dan metodologi yang digunakan untuk mengembangkan sistem-sistem dalam rekayasa sistem. Contoh-contoh metodologi dari pengembangan sistem antara lain waterfall, prototyping, incremental, spiral, dan RAD [9]. Metode pengembangan perangkat lunak yang digunakan oleh penulis adalah metode waterfall.

\section{Model Waterfall}

Model waterfall adalah proses pengembangan perangkat lunak tradisional yang banyak digunakan pada proyek-proyek pengembangan perangkat lunak. Model ini merupakan model sekuensial dimana satu aktivitas menyebabkan dimulainya aktivitas selajutnya [10].

Tahap-tahap utama dari model ini yaitu [11]:

1. Analisis dan definisi persyaratan

Pelayanan, batasan, dan tujuan sistem ditentukan dari konsultasi dengan pengguna sistem. Persyaratan ini selanjutnya didefinisikan dengan rinci yang berfungsi sebagai spesifikasi sistem.

2. Perancangan sistem dan perangkat lunak Proses perancangan sistem membagi persyaratan dalam sistem perangkat keras atau perangkat lunak. Proses ini melibatkan identifikasi dan deskripsi sistem perangkat lunak yang mendasar dan hubungan-hubungannya.

3. Implementasi dan pengujian unit

Pada tahap ini perancangan perangkat lunak direalisasikan menjadi serangkaian program atau unit program. Pengujian unit melibatkan verifikasi atas unit-unit apakah telah memenuhi spesifikasinya.

4. Integrasi dan pengujian sistem

Unit program atau program individual diintegrasikan dan diuji sebagai sistem yang lengkap untuk dikonfirmasikan bahwa persyaratan telah dipenuhi. Setelah sistem diuji, perangkat lunak dikirim kepada pelanggan.

\section{Operasi dan pemeliharaan}

Proses pemeliharaan mencakup perbaikan dari berbagai kesalahan atau error yang tidak ditemukan pada tahap-tahap sebelumnya, perbaikan atas implementasi unit sistem dan pengembangan pelayanan sistem, sementara persyaratan-persyaratan baru ditambahkan. 


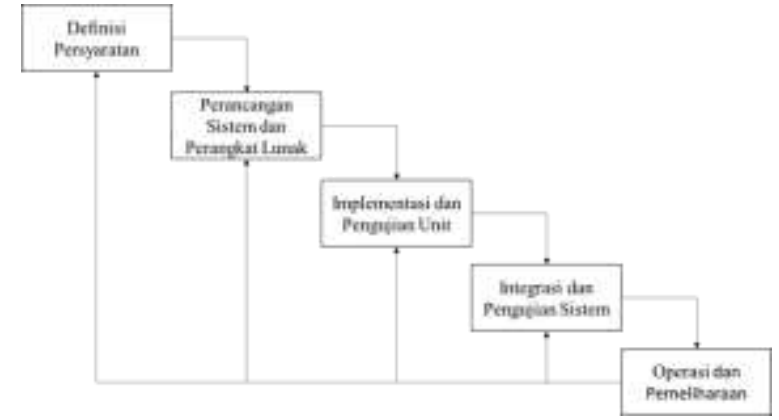

Gambar 1. Model Waterfall

\section{Unified Modelling Language (UML)}

Unified Modelling Language atau UML adalah sebuah teknik pengembangan sistem yang menggunakan bahasa grafis sebagai alat untuk pendokumentasian dan melakukan spesifikasi pada sistem [12]. UML merupakan suatu bahasa yang sudah menjadi standar pada visualisasi, perancangan dan juga pendokumentasian sistem software [13]. UML terdiri dari 13 diagram, namun yang digunakan dalam penelitian ini berjumlah 3 , yaitu [14]

1. Use Case Diagram

Use case Diagram merupakan bentuk pemodelan untuk mengilustrasikan kelakuan (behavior) sistem yang akan dibangun. Use case diagram ini menggambarkan interaksi antara satu atau lebih actor dengan sistem.

\section{Class Diagram}

Class diagram mengilustrasikan struktur sistem dari segi pemberian definisi kelas-kelas yang dibuat saat pembuatan sistem. Class diagram menggambarkan hubungan statis antara jenis-jenis objek dalam sistem.

\section{Activity Diagram}

Sebagian dari state pada activity diagram merupakan action dan sebagian lainnya merupakan transisi yang dipicu oleh state sebelumnya (internal processing). Activity diagram menggambarkan proses-proses dan alur aktivitas dari level atas secara umum.

\section{Black Box Testing}

Testing atau pengujian merupakan cara untuk mendapatkan informasi terhadap kualitas dari suatu sistem atau software dengan melakukan investigasi terhadap software tersebut [15]. Black box testing merupakan salah satu teknik pengujian software yang dimana pengujian hanya terjadi pada tingkat fungsi dasar tanpa perlu menguji kode program [16].

Metode ini merupakan salah satu metode pengujian perangkat lunak yang mudah dilakukan karena hanya memerlukan batas bawah dan batas atas dari data yang diharapkan [17].

\section{METODE}

Adapun peneitian ini menggunakan pendekatan kualitatif dengan alur penelitian sebagai berikut:

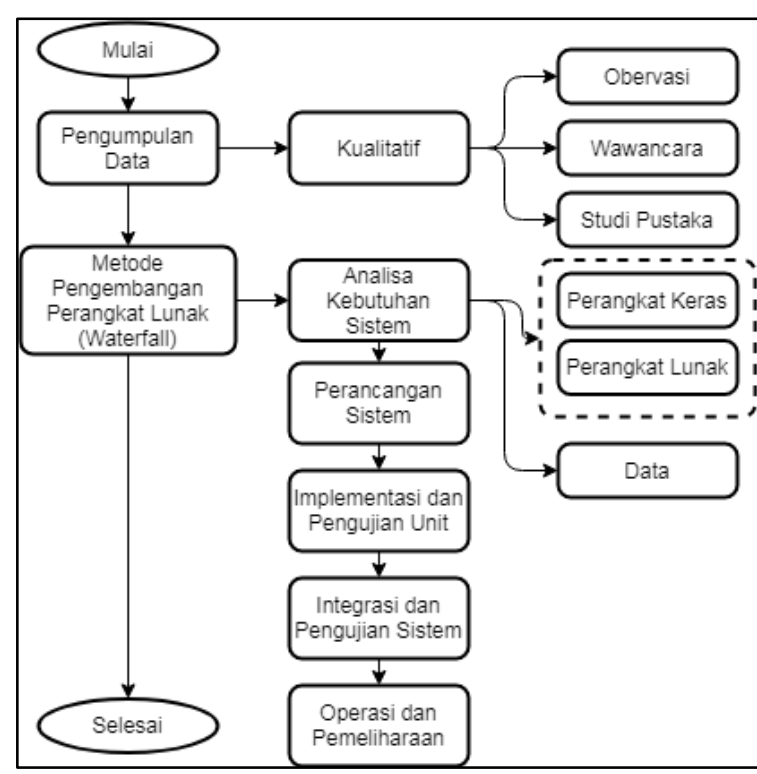

Gambar 2. Alur Penelitian

\section{Metode Pengumpulan Data}

Metode pengumpulan data yang dilakukan peneliti adalah sebagai berikut:

1. Obervasi

Pada tahap ini akan dilakukan observasi dengan cara terjun langsung ke pihak terkait untuk mendapatkan data yang ingin diperoleh. Data-data tersebut berupa data seperti apa sistem pengaduan yang sudah berjalan dan bagaimana proses penanganan pengaduan itu sendiri. Dan juga data mengenai admin dan operator yang akan menangani sistem informasi ini.

\section{Wawancara}

Tahap ini dilakukan dengan cara melakukan wawancara langsung ke bagian sarana dan prasarana dengan bapak Nova dan dengan mas Ahmad Juliansyah bagian DSTI UTS untuk mengetahui kebutuhan konsumen akan sistem informasi ini.

\section{Studi Pustaka.}

Tahap ini dilakukan untuk membantu proses yang berkaitan dengan pembangunan sistem informasi pengaduan layanan, pemrograman web, Pengatuan database dengan $M y S Q L$, dan sebagainya.

\section{Metode Pengembangan Perangkat Lunak}

Metode pengembangan perangkat lunak yang digunakan dalam penelitian ini adalah model waterfall. Alasan penulis menggunakan metode ini adalah karena metode ini memiliki urutan tahapan sistematis yang harus diselesaikan sebelum lanjut ke tahap selanjutnya sehingga sistem yang dihasilkan sesuai dengan harapan. Berikut ini merupakan 
langkah-langkah yang akan dilakukan peneliti dalam membangun sistem menggunakan model waterfall.



Gambar 3. Metode Pengembangan Perangkat Lunak

Penjabaran dari tahapan gambar di atas adalah sebagai berikut:

1. Analisis dan definisi persyaratan

Pada tahap ini peneliti akan melakukan analisis terhadap kebutuhan atau spesifikasi dari sistem dengan cara melakukan konsultasi terhadap pengguna sistem

2. Perancangan sistem dan perangkat lunak Pada tahap perancangan dilakukan identifikasi dan deskripsi terhadap sistem informasi pengaduan layanan sarpras yang akan dibangun dari informasi yang didapatkan pada tahap sebelumnya.

3. Implementasi dan pengujian unit

Pada tahap hasil perancangan sistem informasi pengaduan layanan sarpras direalisasikan menjadi serangkaian program atau unit program. Lalu dilakukan pengujian unit untuk melihat apakah unitunit yang telah dirancanng telah memenuhi spesifikasi yang diinginkan.

4. Integrasi dan pengujian sistem

Unit-unit dari Sistem informasi pengaduan layanan sarpras yang telah direalisasikan sebelumnya digabung menjadi sistem yang lengkap lalu diuji memastikan persyaratan terpenuhi. Lalu perangkat lunak dikirm kepada konsumen.

5. Operasi dan pemeliharaan

Pada tahap ini dilakukan pemeliharaan terhadap sistem informasi pengaduan layanan sarpras. Dan jika seandainya ada persyaratan baru makan akan ditambahkan di tahap ini.

\section{HASIL DAN PEMBAHASAN}

Menimbang dari permasalahan yang telah diuraikan sebelumnya maka peneliti merancang diagram penggambaran sistem yang dapat dilihat berikut ini:

\section{Use Case Diagram Proses Bisnis}

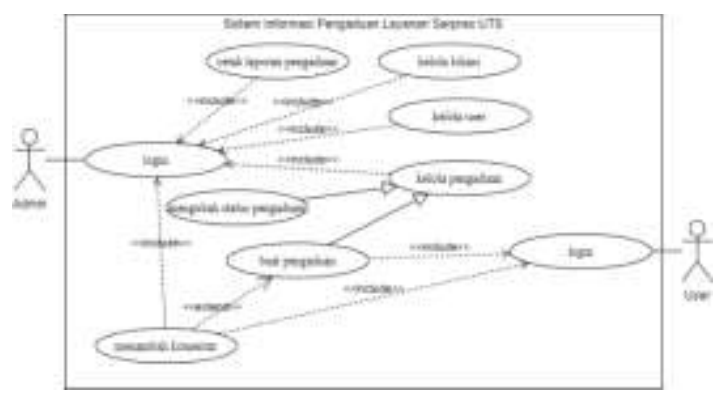

Gambar 4. Use Case Diagram Proses Bisnis

Sebelum dapat menggunakan fitur pengaduan, pengguna baik admin maupun user harus melalui proses login terlebih dahulu.

\section{Activity Diagram Login}

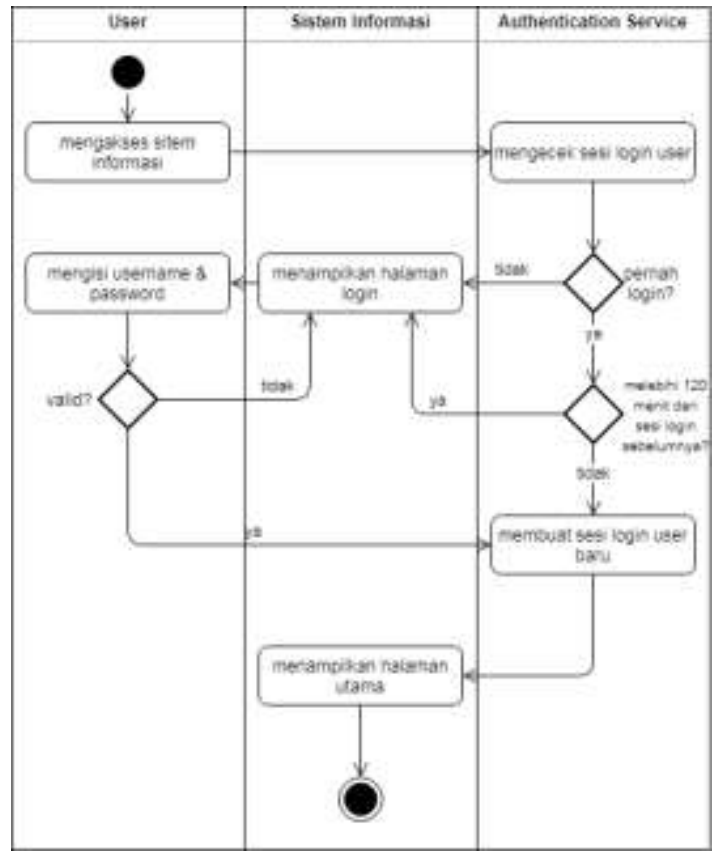

Gambar 5. Activity Diagram Login

Pada proses login, saat user mengakses halaman utama maka akan diperiksa apakah sudah ada sesi login sebelumnya, jika sudah maka akan langsung masuk ke menu utama, jika belum maka user diperlukan untuk login. Walaupun sebelumnya user memiliki sesi login, jika telah melebihi 120 menit dari sesi sebelumnya, maka user harus login kembali untuk dapat mengakses halaman utama. 
Activity Diagram Alur Pengaduan



Gambar 6. Activity Diagram Alur Pengaduan

Pada proses pengaduan, user membuat pengaduan yang ditampilkan pada sistem informasi, lalu akan dikelola oleh admin terkait status pengaduan. Status pengaduan telah selesai, admin dapat menambahkan detail gambar kondisi sebelum dan sesudah diperbaiki.

\section{Implementasi Program}

Berikut ini merupakan implementasi Sistem Informasi Pengaduan Layanan Sarana dan Prasarana Universitas Teknologi Sumbawa:

a. Implementasi Halaman Utama

Di bawah ini merupakan implementasi tampilan dari halaman utama admin dimana menu pada navigasi lengkap

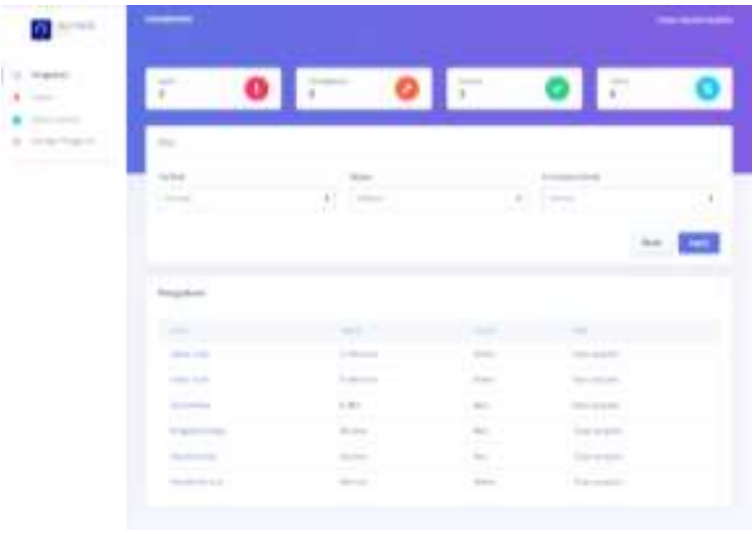

Gambar 7. Halaman Utama

b. Implementasi Halaman Detail Pengaduan

Di bawah ini merupakan implementasi tampilan dari halaman detail pengaduan

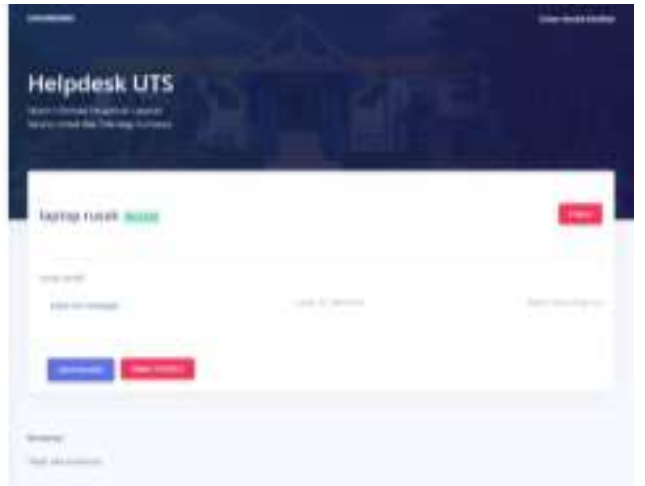

Gambar 8. Halaman Detail Pengaduan

c. Implementasi Halaman Buat Pengaduan Berikut ini merupakan implementasi tampilan dari halaman buat pengaduan

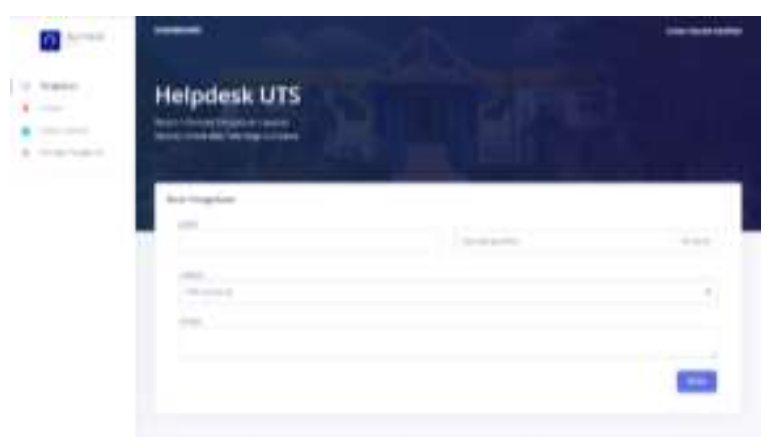

Gambar 9. Halaman Buat Pengaduan

d. Implementasi Halaman Login

Di bawah ini merupakan implementasi dari halaman login

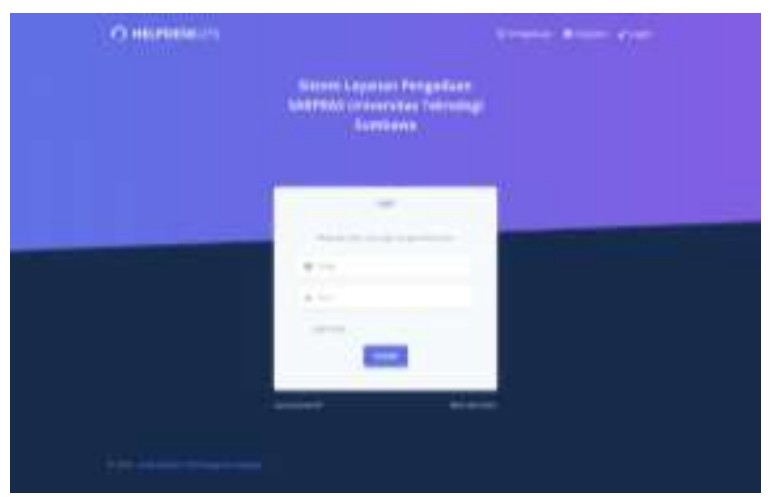

Gambar 10. Halaman Login Akun 
e. Implementasi Halaman Tambah Lokasi Berikut ini merupakan implementasi tampilan halaman tambah lokasi

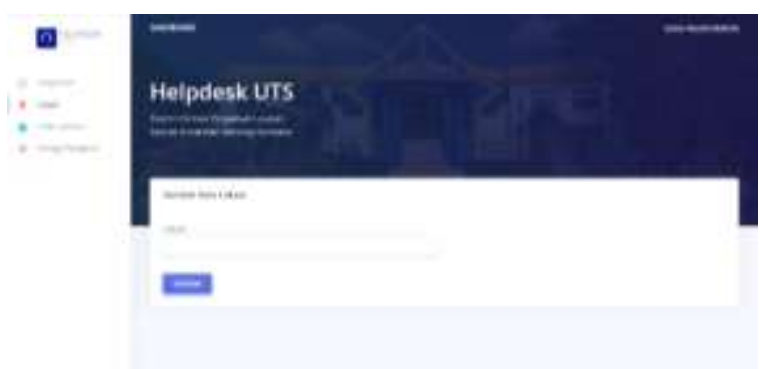

Gambar 11. Halaman Tambah Lokasi

f. Halaman Pengaturan Cetak Laporan

Berikut ini merupakan implementasi tampilan halaman pengaturan cetak laporan

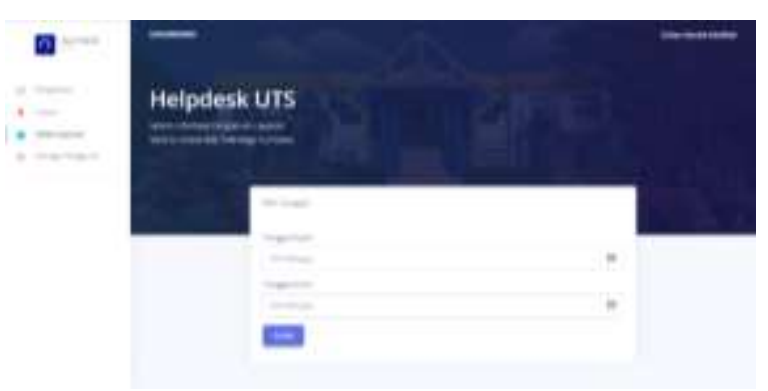

Gambar 12. Halaman Pengaturan Cetak Laporan

g. Implementasi Halaman Cetak Laporan

Berikut ini merupakan implementasi tampilan halaman cetak laporan

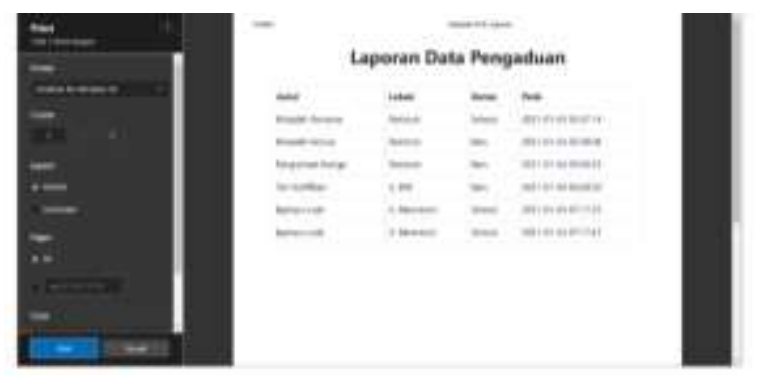

Gambar 13. Halaman Cetak Laporan

h. Halaman Daftar User

Di bawan ini merupakan implementasi tampilan halaman daftar $u s e r$



Gambar 14. Halaman Daftar User i. Halaman Buat User

Di bawah ini merupakan implementasi tampilan halaman buat user

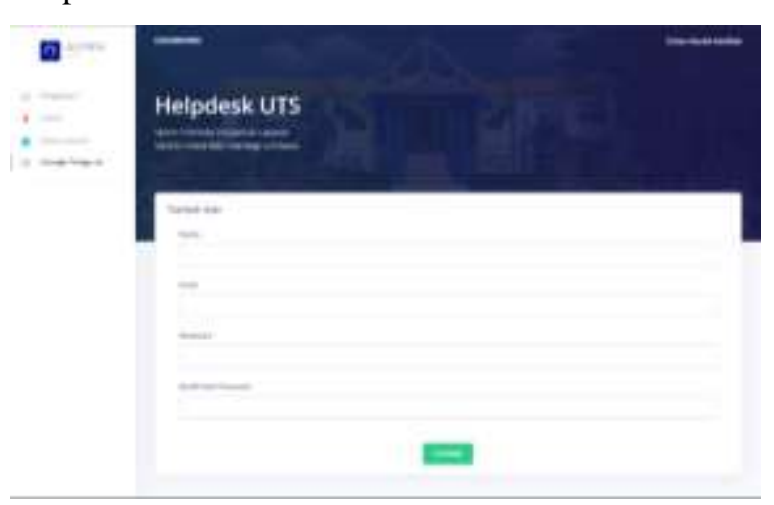

Gambar 15. Halaman Buat User

\section{Pengujian Sistem}

Hasil pengujian terhadap Sistem Informasi Pengaduan Layanan Sarpras UTS yang dilakukan oleh beberapa responden teman-teman mahasiswa dan admin sarana dan prasarana UTS adalah sebagai berikut:

1. Pengujian Halaman Login

Berikut ini merupakan hasil pengujian pada halaman login

Tabel 1. Pengujian Halaman Login

\begin{tabular}{|c|c|c|}
\hline Aktivitas & Hasil & $\begin{array}{c}\text { Persentase } \\
\text { Keberhasilan }\end{array}$ \\
\hline $\begin{array}{c}\text { Memasukkan } \\
\text { data login user } \\
\text { yang valid } \\
\text { hemasukkan } \\
\text { data login } \\
\text { admin yang } \\
\text { valid }\end{array}$ & $\begin{array}{c}\text { Menaman user } \\
\text { henampilkan } \\
\text { halaman } \\
\text { utama admin }\end{array}$ & $100 \%$ \\
\hline $\begin{array}{c}\text { Memasukkan } \\
\text { data login } \\
\text { admin yang } \\
\text { valid }\end{array}$ & $\begin{array}{c}\text { Menampilkan } \\
\text { halaman } \\
\text { utama teknisi }\end{array}$ & $100 \%$ \\
\hline $\begin{array}{c}\text { Memasukkan } \\
\text { data login } \\
\text { yang tidak } \\
\text { valid }\end{array}$ & $\begin{array}{c}\text { Menampilkan } \\
\text { pesan } \\
\text { "username/pa } \\
\text { ssword salah" }\end{array}$ & $100 \%$ \\
\hline $\begin{array}{c}\text { Tidak mengisi } \\
\text { form login }\end{array}$ & $\begin{array}{c}\text { Menampilkan } \\
\text { pesan "please } \\
\text { fill out this } \\
\text { field" }\end{array}$ & $100 \%$ \\
\hline
\end{tabular}


2. Pengujian Halaman Registrasi Akun Berikut ini merupakan hasil pengujian dari halaman registrasi akun

Tabel 2. Pengujian Halaman Registrasi Akun

\begin{tabular}{|c|c|c|}
\hline Aktivitas & Hasil & $\begin{array}{c}\text { Persentase } \\
\text { Keberhasilan }\end{array}$ \\
\hline $\begin{array}{c}\text { Mengisi } \\
\text { seluruh form } \\
\text { sesuai format } \\
\text { dan klik } \\
\text { registrasi }\end{array}$ & $\begin{array}{c}\text { Menampilkan } \\
\text { halaman } \\
\text { utama dengan } \\
\text { user baru } \\
\text { terotentikasi }\end{array}$ & $100 \%$ \\
\hline $\begin{array}{c}\text { Mengisi hanya } \\
\text { sebagian form } \\
\text { dan klik } \\
\text { registrasi }\end{array}$ & $\begin{array}{c}\text { Menampilkan } \\
\text { pesan "please } \\
\text { fill out this } \\
\text { field" pada } \\
\text { form yang } \\
\text { belum diisi }\end{array}$ & \\
\hline
\end{tabular}

3. Pengujian Halaman Kelola Pengaduan Berikut ini merupakan hasil pengujian halaman kelola pengaduan

Tabel 3. Pengujian Halaman Kelola Pengaduan

\begin{tabular}{|c|c|c|}
\hline Aktivitas & Hasil & $\begin{array}{c}\text { Persentasi } \\
\text { Keberhasilan }\end{array}$ \\
\hline $\begin{array}{c}\text { Mengisi } \\
\text { seluruh form } \\
\text { pengaduan dan } \\
\text { klik simpan }\end{array}$ & $\begin{array}{c}\text { Kembali ke } \\
\text { daftar } \\
\text { pengaduan } \\
\text { dan muncul } \\
\text { data baru } \\
\text { pada daftar }\end{array}$ & $100 \%$ \\
\hline $\begin{array}{c}\text { Tidak mengisi } \\
\text { form dan klik } \\
\text { simpan }\end{array}$ & $\begin{array}{c}\text { Menampilkan } \\
\text { pesan isi form } \\
\text { sesuai dengan } \\
\text { form yang } \\
\text { belum diisi }\end{array}$ & $100 \%$ \\
\hline $\begin{array}{c}\text { Menekan } \\
\text { tombol hapus } \\
\text { pada halaman } \\
\text { detail }\end{array}$ & $\begin{array}{c}\text { Pengaduan } \\
\text { terhapus dan } \\
\text { kembali ke } \\
\text { halaman } \\
\text { utama }\end{array}$ & $100 \%$ \\
\hline $\begin{array}{c}\text { Mengaduan } \\
\text { data pada } \\
\text { pengaduan dan } \\
\text { klik ubah }\end{array}$ & $\begin{array}{c}\text { Data pada } \\
\text { pengaduan } \\
\text { berubah }\end{array}$ & \\
\hline \multicolumn{2}{|c|}{$100 \%$} \\
\hline
\end{tabular}

4. Pengujian Halaman Kelola Lokasi

Berikut ini merupakan hasil pengujian halaman kelola lokasi

Tabel 4. Pengujian Halaman Kelola Lokasi

\begin{tabular}{|c|c|c|}
\hline Aktivitas & Hasil & $\begin{array}{c}\text { Persentase } \\
\text { Keberhasilan }\end{array}$ \\
\hline $\begin{array}{c}\text { Memasukkan } \\
\text { nama lokasi } \\
\text { dan klik } \\
\text { tombol tambah }\end{array}$ & $\begin{array}{c}\text { Kembali ke } \\
\text { halaman } \\
\text { daftar lokasi } \\
\text { dengan data } \\
\text { lokasi masuk } \\
\text { dalam daftar }\end{array}$ & $100 \%$ \\
\hline
\end{tabular}

\begin{tabular}{|c|c|c|}
\hline $\begin{array}{c}\text { Mengisi hanya } \\
\text { sebagian form } \\
\text { dan klik } \\
\text { tombol tambah }\end{array}$ & $\begin{array}{c}\text { Menampilkan } \\
\text { pesan isi form } \\
\text { sesuai dengan } \\
\text { form yang } \\
\text { belum diisi }\end{array}$ & $100 \%$ \\
\hline $\begin{array}{c}\text { Kembali ke } \\
\text { halaman } \\
\text { Mengubah } \\
\text { daftar lokasi } \\
\text { dengan data } \\
\text { lan klik ubahi }\end{array}$ & $100 \%$ \\
$\begin{array}{c}\text { lokasi } \\
\text { derhasil } \\
\text { diubah }\end{array}$ & \\
\hline $\begin{array}{c}\text { Menghapus } \\
\text { lokasi dengan } \\
\text { menekan } \\
\text { tombol hapus } \\
\text { pada daftar } \\
\text { lokasi }\end{array}$ & $\begin{array}{c}\text { daftar lokasi } \\
\text { ter-refresh } \\
\text { dan data } \\
\text { lokasi } \\
\text { terhapus }\end{array}$ & \\
\hline \multicolumn{2}{|c}{$100 \%$} \\
\hline
\end{tabular}

5. Pengujian Halaman Kelola User Berikut ini merupakan hasil pengujian halaman kelola user

Tabel 5. Pengujian Halaman Kelola User

\begin{tabular}{|c|c|c|}
\hline Aktivitas & Hasil & $\begin{array}{c}\text { Persentase } \\
\text { Keberhasilan }\end{array}$ \\
\hline $\begin{array}{c}\text { Mengisi } \\
\text { seluruh form } \\
\text { sesuai format } \\
\text { dan klik } \\
\text { tombol tambah } \\
\text { halaman } \\
\text { daftar user } \\
\text { dengan data } \\
\text { user berhasil } \\
\text { ditambah }\end{array}$ & $100 \%$ \\
\hline $\begin{array}{c}\text { Mengisi hanya } \\
\text { sebagian form } \\
\text { dan klik }\end{array}$ & $\begin{array}{c}\text { Menampilkan } \\
\text { pesan isi form } \\
\text { sesuai dengan } \\
\text { tombol tambah } \\
\text { belum diisi }\end{array}$ & $100 \%$ \\
\hline $\begin{array}{c}\text { Menghapus } \\
\text { user dengan } \\
\text { klik tombol } \\
\text { hapus pada } \\
\text { halaman daftar } \\
\text { user }\end{array}$ & $\begin{array}{c}\text { Data user } \\
\text { berhasil } \\
\text { dihapus me- } \\
\text { refresh } \\
\text { halaman } \\
\text { daftar user }\end{array}$ & \\
\hline \multicolumn{2}{|c|}{$100 \%$} \\
\hline
\end{tabular}
6. Pengujian Halaman Cetak Laporan
Pengaduan

Berikut ini merupakan hasil pengujian halaman cetak laporan

Tabel 6. Pengujian Halaman Cetak Laporan

\begin{tabular}{|c|c|c|}
\hline Aktivitas & Hasil & $\begin{array}{c}\text { Persentase } \\
\text { Keberhasilan }\end{array}$ \\
\hline Menentukan & Membuka tab & $100 \%$ \\
jarak tanggal & baru dan & \\
pada halaman & menampilkan & \\
pengaturan & pengaduan & \\
cetak sebelum & sesuai dengan & \\
dan sesudah & jarak tanggal & \\
lalu klik & yang telah & \\
tombol cetak & ditentukan & \\
\hline
\end{tabular}


7. Pengujian Halaman Profil

Beikut ini merupakan hasil pengujian halaman profil

Tabel 7. Pengujian Halaman Profil

\begin{tabular}{|c|c|c|}
\hline Aktivitas & Hasil & $\begin{array}{c}\text { Persentase } \\
\text { Keberhasilan }\end{array}$ \\
\hline $\begin{array}{c}\text { Menekan } \\
\text { tombol profil }\end{array}$ & $\begin{array}{c}\text { Masuk ke } \\
\text { halaman } \\
\text { profil dan } \\
\text { menampilkan } \\
\text { data user }\end{array}$ & $100 \%$ \\
\hline
\end{tabular}

8. Pengujian Logout

Berikut ini merupakan hasil pengujian logout

Tabel 8. Pengujian Logout

\begin{tabular}{|c|c|c|}
\hline Aktivitas & Hasil & $\begin{array}{c}\text { Persentasi } \\
\text { Keberhasilan }\end{array}$ \\
\hline $\begin{array}{c}\text { Menekan } \\
\text { tombol logout }\end{array}$ & $\begin{array}{c}\text { Kembali ke } \\
\text { halaman } \\
\text { login }\end{array}$ & $100 \%$ \\
\hline
\end{tabular}

\section{KESIMPULAN DAN SARAN}

\section{Simpulan}

Peneliti telah berhasil membangun Sistem Informasi Pengaduan Layanan Sarpras Universitas Teknologi Sumbawa Berbasis Web menggunakan metode waterfall, Bahasa pemrograman PHP, dan framework Laravel. Sistem informasi pengaduan layanan sarpras Universitas Teknologi Sumbawa berhasil diimplementasikan dan sudah dapat digunakan oleh Biro Sarana dan Prasarana dan Civitas Akademika UTS untuk membuat dan mengatur pengaduan. Pengujian dengan metode black box yang dilakukan oleh beberapa responden menunjukkan rata-rata keberhasilan uji coba $100 \%$ yang menandakan bahwa sistem informasi ini berjalan dengan baik.

\section{Saran}

Peneliti menyadari dengan banyaknya kekurangan dalam sistem informasi yang dibangun ini seperti tidak adanya fitur pemberian rating, pengkategorian, live-chat dll. Adapun saran dari peneliti ialah agar melakukan pengembangan lebih lanjut terhadap kekurangan dari sistem informasi ini agar menjadi lebih layak.

\section{DAFTAR PUSTAKA}

M. Naomi and H. Noprisson, "Analisa Dan Perancangan Sistem Pengaduan Mahasiswa Berbasis Web ( Studi Kasus : Universitas Mercu Buana Kranggan )," JUSIBI (Jurnal Sist. Inf. Dan E-Bisnis, vol. 1, no. 5, pp. 185-193, 2019.

[2]
Akademik Menggunakan Responsive Web Design," Sisfokom, vol. 08, no. 1, pp. 39-45, 2019.

[3] I. G. T. Suryawan and I. P. S. Handika, "Rancang Bangun Sistem Pengaduan Layanan Akademik Stmik Stikom Indonesia," SINTECH (Science Inf. Technol. J., vol. 1, no. 2, pp. 121-133, 2018, doi: 10.31598/sintechjournal.v1i2.279.

[4] Anofrizen, "Sistem Informasi Pengaduan Masyarakat Program Keluarga Harapan Kota Pekanbaru (Studi Kasus: Dinas Sosial Dan Pemakaman Kota Pekanbaru)," J. Ilm. Rekayasa dan Manaj. Sist. Inf., vol. 3, no. 1, pp. 97-101, 2017.

[5] N. D. Sofya, "Rancang Bangun Aplikasi Kamus Bahasa Sumbawa Berbasis Android," Universitas Teknologi Sumbawa, 2017.

[6] J. Hutahaean, Konsep Sistem Informasi. Yogyakarta: Deepublish, 2015.

[7] R. Indonesia, "Peraturan Presiden Nomor 9 Tahun 2013." 2013.

[8] "Arti kata layan - Kamus Besar Bahasa Indonesia (KBBI) Online." https://kbbi.web.id/layan (accessed Dec. 27, 2020).

[9] F. Sari, Metode dalam Pengambilan Keputusan. Yogyakarta: Deepublish, 2018.

[10] I. Fahrurrozi and A. SN, "Proses Pemodelan Software Dengan Metode Waterfall Dan Extreme Programming: Studi Perbandingan," J. Online STMIK, vol. 1, no. 2012, p. 120, 2015, [Online]. Available: mediakom-penerbit.com.

[11] I. Sommerville, Software Engineering Jl. 1. Jakarta: Erlangga, 2003.

[12] S. Mulyani, Metode Analisis dan Perancangan Sistem. Bandung: Abdi Sistematika, 2017.

[13] B. Haqi, Aplikasi SPK Pemilihan Dosen Terbaik Metode Simple Additive Weighting (SAW) Dengan Java. Yogyakarta: Deepublish, 2019.

[14] K. Harianto, H. Pratiwi, and Y. Suhariyadi, Sistem Monitoring Lulusan Perguruan Tinggi Dalam Memasuki Dunia Kerja Menggunakan Tracer Study. Surabaya: Media Sahabat Cendekia, 2019.

[15] A. Azis, I. Setiawan, and D. Krisbiantoro, Panduan Pemilu Desa Berbasis Website (Teknologi Sistem Cerdas Dan Implementasi Di Masyarakat). Yogyakarta: Deepublish, 2019.

[16] S. Desikan and G. Ramesh, Software Testing: Principles and Practice. Delhi: Pearson Education India, 2006.

[17] M. S. Mustaqbal, R. F. Firdaus, and H. Rahmadi, "Pengujian Aplikasi Menggunakan Black Box Testing Boundary Value Analysis (Studi Kasus : Aplikasi Prediksi Kelulusan SNMPTN)," vol. I, no. 3, pp. 31-36, 2015. 